\title{
Long-term effects of anterior temporal lobectomy on certain cognitive functions
}

\author{
C. B. BLAKEMORE AND MURRAY A. FALCONER \\ From the Guy's-Maudsley Neurosurgical Unit and the Institute of Psychiatry \\ (University of London), Maudsley Hospital, London
}

The changes in cognitive functions following upon anterior temporal lobectomy, carried out for the relief of epilepsy, have aroused considerable interest during the past decade. Most studies have demonstrated that after a unilateral operation there is a differential impairment in psychological functions which is dependent upon whether the operation was carried out on the dominant or non-dominant cerebral hemisphere. Thus Meyer and Yates (1955) and Meyer $(1957 ; 1959)$ showed that after removal of the anterior $6 \mathrm{~cm}$. or so of the left or dominant temporal lobe the ability is impaired to learn new verbal material presented auditorily in the form of paired-associates, but that there is no evidence of such an impairment after a comparable righthemisphere (non-dominant) operation. In all their studies assessments were made for each patient both preoperatively and approximately one month postoperatively, while Meyer (1959) also followed up his patients one year after operation and found that the left-temporal lobe group still remained severely impaired in this ability. This auditory-verbal learning deficit was also shown to be independent of transient dysphasic symptoms following operation.

Milner $(1954 ; 1958)$ was able to demonstrate an impairment for both story-recall and verbal pairedassociate learning after left-sided but not after right-sided temporal lobectomy, and also that these impairments were still present one to two years after operation. From these and subsequent studies she argues that the impairment is essentially one related to the verbal nature of the materials irrespective of the modality of presentation, and that the cognitive impairments following right-hemisphere operation are associated with non-verbal materials. Such an interpretation was not supported by Meyer (1959) who was unable to find any impairment in the learning of verbal paired-associates presented visually to patients who had undergone a lefthemisphere operation. An unpublished study by one of us (C.B.B.) suggests, however, that the rate of presentation of the materials to be learned may be a significant variable, and that the experimental conditions involved in Meyer's investigation consequently did not reveal a visual-verbal learning deficit.

Clinical observation of patients who have undergone removal of the dominant temporal lobe often brings out the cognitive deficits from which they suffer, in that the more intelligent patients and those whose work is dependent upon verbal learning frequently complain of poor memory. This failure of memory is particularly obvious in respect of everyday events, such as the recall of verbal instructions, of conversations, or of items of shopping they have been requested to obtain. Indeed, these complaints of auditory and verbal memory impairment are so frequent after dominant temporal lobectomy that Hill (1958) felt reluctant to recommend operation on the left side in an epileptic patient not above average intelligence. We have been impressed, however, by the fact that, if patients are followed up over a number of years, such complaints and obvious manifestations of memory deficit seem to disappear. Although the follow-up studies carried out by Meyer and by Milner would suggest that the learning and memory impairments are still present one to two years after operation, and are therefore likely to be relatively stable, this does not seem to accord with the patients' social and vocational adjustment in many important respects. We have observed, for example, a young business executive who, following a dominant temporal lobectomy, developed a number of auditory learning deficits. However, within three to four years he had acquired fluency of speech in two foreign languages, largely derived from a study of gramophone records coupled with his personal experience of travelling in European countries concerned on behalf of his firm. He would even carry out long business conversations by telephone in these newly acquired languages without recourse to notes. Again we have had experience of a long-distance telephone operator, who, following operation, had to give up this work as he could not 
readily recollect telephone numbers given to him. However, some years later he found he could now do this work again. It was observations such as these that led us to ascertain whether the cognitive deficits observed following left temporal lobectomy and still present up to two years later had either been compensated for in some way or had disappeared. The possibility that such a process was likely to be observed was strengthened by the report of Lansdell (1962) that after right temporal lobectomy certain of the non-verbal impairments were transient.

The present investigation, therefore, was carried out in order to study the possibility that certain of the psychological deficits known to be present after dominant temporal lobectomy might prove to be transient, and that partial or complete recovery would occur over a period of years.

\section{METHOD}

Most patients who have undergone a temporal lobectomy for epilepsy in the Guy's-Maudsley Neurosurgical Unit are regularly followed up and are seen, if physically possible, at least at yearly intervals for a period of at least 10 years. Eighty-six patients who had undergone an anterior temporal lobectomy since 1954 were traced, 54 having had a left temporal lobectomy and 32 a right one. All of them were right-handed, and a variety of evidence from neurological and psychological assessments, such as dysphasic episodes, as well as from cortical stimulation at the time of operation leading to speech arrest, indicated that the left-sided patients had been operated upon the dominant hemisphere while the rightsided patients had undergone operations upon the non-dominant hemisphere. Every patient had been tested on alternative forms of a battery of paired-associates learning tasks as described by Meyer (1959) on at least three occasions before the present investigation was begun, namely, before operation, within two months of operation, and one year after operation.

These tasks had been administered either for research purposes in the earlier years, or as part of a general psychological assessment of the patient's abilities and deficits before and after operation. Many of the patients had actually been studied up to one year after operation by Meyer himself, and we were later able to obtain data on the current status of approximately $85 \%$ of his original
1959 sample at periods of up to 12 years after operation. At the time of our investigation 11 of the subjects (seven left and four right) had been operated upon 10 or more years previously, 15 (10 left, five right) between eight and nine years, 14 (nine left, five right) between six and seven years, 17 (10 left, seven right) between four and five years, and 29 (18 left, 11 right) between two and three years previously. In the early postoperative periods all the patients who had undergone a left temporal lobectomy were known to have shown an impairment of verbal paired-associates learning for auditorily presented materials.

As our chief interest was to ascertain what had happened to learning and retention during the years following operation, we studied only verbal pairedassociate learning of auditorily presented materials, which both Meyer (1959) and Milner (1958) had found to be impaired after a left temporal lobectomy. The subjects were required to learn each pair of words to a criterion of three correct repetitions, and for this purpose we used either the alternate forms of eight pair-lists of meaningful words developed by Meyer (1959), or newly developed lists of a similar nature which were known to be sensitive to the learning deficits following immediately after operation. These later lists were included to exclude the possibility that changes in performance might be due to practice effects. These lists were learned both by the method of unaided recall and by the method of recognition and selection. The scores derived from these learning tasks are based on the number of errors the subject makes before he reaches the criterion of having learned the complete list of eight pairs.

\section{RESULTS}

Table I shows the I.Q. from the Wechsler intelligence scales for the left and right hemisphere operated groups. It will be seen from these data that the two groups and their respective subgroups do not change significantly over the various time intervals after operation, except that there is a significant drop in the verbal I.Q. of the lefthemisphere group and of performance I.Q. in the right-hemisphere group immediately after operation. These changes recover, however, to the preoperative level within one year of operation, and therefore it would seem that I.Q. changes alone do not account for variations in learning capacity.

TABLE I

MEAN I.Q. DATA ON LEFT AND RIGHT HEMISPHERE OPERATED GROUPS

Preoperative Postoperative

\begin{tabular}{|c|c|c|c|c|c|c|c|c|}
\hline & & & & & & & & \\
\hline & & $\begin{array}{l}\text { Within } \\
\text { Two Months }\end{array}$ & One Year & $\begin{array}{l}\text { Two to } \\
\text { Three Years }\end{array}$ & $\begin{array}{l}\text { Four to } \\
\text { Five Years }\end{array}$ & $\begin{array}{l}\text { Six to } \\
\text { Seven Years }\end{array}$ & $\begin{array}{l}\text { Eight to } \\
\text { Nine Years }\end{array}$ & $\begin{array}{l}\text { Ten or } \\
\text { More Years }\end{array}$ \\
\hline $\begin{array}{l}\text { Left hemisphere N } \\
\text { Verbal I.Q. } \\
\text { Performance I.Q. } \\
\text { Right hemisphere N } \\
\text { Verbal I.Q. } \\
\text { Performance I.Q. }\end{array}$ & $\begin{array}{c}54 \\
96 \cdot 7 \\
103 \cdot 3 \\
32 \\
102 \cdot 3 \\
97 \cdot 4\end{array}$ & $\begin{array}{c}54 \\
81 \cdot 2 \\
100 \cdot 7 \\
32 \\
100 \cdot 1 \\
90 \cdot 2\end{array}$ & $\begin{array}{c}54 \\
94 \cdot 6 \\
106 \cdot 9 \\
32 \\
103 \cdot 5 \\
98 \cdot 1\end{array}$ & $\begin{array}{c}18 \\
93 \cdot 8 \\
102 \cdot 5 \\
11 \\
102 \cdot 6 \\
95 \cdot 9\end{array}$ & $\begin{array}{c}10 \\
97 \cdot 8 \\
106 \cdot 3 \\
7 \\
101 \cdot 1 \\
96 \cdot 9\end{array}$ & $\begin{array}{c}9 \\
100 \cdot 1 \\
102 \cdot 3 \\
5 \\
101 \cdot 3 \\
97 \cdot 1\end{array}$ & $\begin{array}{c}10 \\
93 \cdot 4 \\
100 \cdot 2 \\
5 \\
99 \cdot 3 \\
100 \cdot 2\end{array}$ & $\begin{array}{c}7 \\
97.5 \\
104 \cdot 3 \\
4 \\
104 \cdot 9 \\
97 \cdot 2\end{array}$ \\
\hline
\end{tabular}


TABLE II

PERFORMANCE OF TEMPORAL LOBECTOMY PATIENTS ON AUDITORY VERBAL PAIRED-ASSOCIATE LEARNING TASKS PREOPERATIVELY, WITHIN TWO MONTHS OF OPERATION, ONE YEAR POSTOPERATIVELY, AND AT VARIOUS POSTOPERATIVE INTERVALS AFTER ONE YEAR

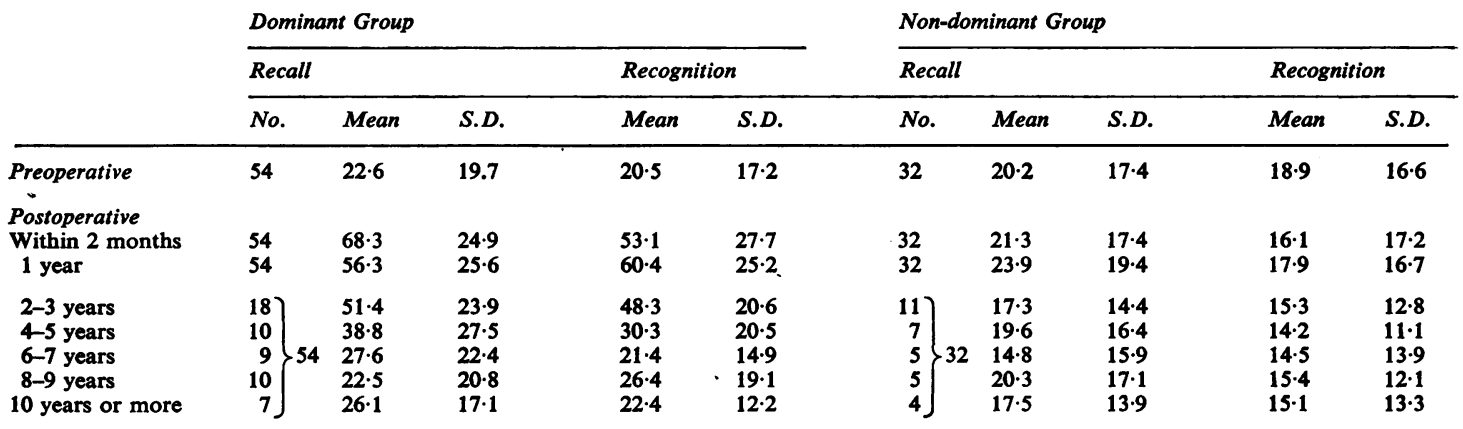

The main results of this investigation are shown in Table II which presents data for the left- and righthemisphere groupings of patients at various post-operative periods of from two to 10 years, compared with each groups' performance preoperatively, two months after operation, and one year postoperatively.

It will be seen from these data that a significant trend occurs in the case of the left-hemisphere patients up to the fourth and fifth postoperative years, but that no significant changes occur in the performances of the right-hemisphere group which thus acts as a control. Analysis of the results show that after operation most patients in the lefthemisphere group are markedly impaired in auditory verbal learning ability, and that little improvement occurs within the first two to three years. However, after that time rapid improvement is observed. An analysis of variance for trend in the postoperative data of the dominant temporal lobe patients for recall and recognition combined is highly significant $(F=13.72 ; P=<0.001)$. After the fifth postoperative year the mean performance of this group has returned to within the limits of its preoperative level. Analysis of variance also shows a highly significant difference between the postoperative trends of the left- and right-hemisphere groups, and this is due to the fact that the nondominant group shows no evidence of change in performance pre- to postoperatively or at any stage after operation $(F=7.91 ; P=<0.001)$. In order to ensure that these trends do reflect an actual process of recovery we calculated the exact change in the error scores on each learning task for each individual subject. These calculations show that recovery does take place, and that the lower mean scores for the dominant hemisphere operated patients at the later postoperative periods cannot be accounted for on the basis of them not having experienced learning difficulties immediately after operation or one year postoperatively.

Analysis of our data revealed that often there were marked individual differences within the subgroupings of the left-hemisphere patients between the second and tenth years postoperatively, and that the learning deficit appeared to persist in some patients longer than in others. With this observation in mind correlations were obtained between the changes in pre- and postoperative levels at the various time intervals measured in years with the extent of tissue removed at the time of operation, the age of the patient at the time of operation, and the outcome of operation in respect of whether the patient's seizures were 'markedly improved', 'improved', or 'unchanged' (Falconer and Serafetinides, 1963). The correlation with extent of operation was not significant $(r=0.13 ; P=>0 \cdot 10)$, but was highly significant for both age at the time of operation $(\mathrm{r}=0.49 ; \mathrm{P}=<0.01)$ and change in seizure frequency after operation $(\mathrm{r}=0.58 ; \mathrm{P}=$ $<0.001)$.

\section{DISCUSSION}

This study confirms the clinical impression that auditory verbal learning difficulties noted after operation on the dominant temporal lobe are not permanent, but that they disappear in the course of time, lasting an average of three to five years. Similarly, Cordeau and Mahut (1964) found that in a long-term study of post-ablation temporal lobe deficits on complex auditory and visual discrimination tasks in monkeys, some animals appeared to show recovery of functions after a number of years. Such findings show the fallacy of presuming that, because a learning deficit is present a year or more after operation, such a deficit will persist permanently. We have, however, shown that the rate of 
recovery in patients is adversely influenced by the increasing age of the patient at the time of operation, and by the continued occurrence of fits. The study does show evidence of the plasticity of the brain in its learning functions. Obviously, some reorganization of the brain has taken over the functions formerly subserved by the dominant temporal lobe that was excised, and it is but natural to presume that the contralateral or minor temporal lobe may have played a part.

Further research aimed at understanding this process of reorganization of function after operation on the temporal lobes is obviously needed, and in particular a more detailed description of the influence of variables affecting performance on the learning tasks employed, such as the strategies employed in learning and the effect of different methods of presenting the materials to be learned. From such studies it should be possible to describe the exact nature of the deficits which show recovery as a consequence of the presumed reorganization of brain function. It is along such lines that our current research is proceeding.

\section{SUMMARY}

In a long-term study of 86 patients submitted to a partial anterior temporal lobectomy for epilepsy, it has been shown that an auditory verbal learning deficit usually appears after removal of the dominant temporal lobe. This deficit may persist for three or so years, but thereafter usually progressively recovers. The speed of recovery varies with the age of the patient at the time of operation and the persistence of fits after operation. Attention is drawn to the caution necessary when inferring that a cognitive deficit known to be present a year or so after brain surgery is permanent, for the plasticity of the brain and behaviour relationships can be greater than hitherto imagined.

We wish to thank Dr. Victor Meyer, now Senior Lecturer in Psychology, Middlesex Hospital Medical School, London, for his considerable assistance in identifying the patients he used in his earlier investigation.

One of us (M.A.F.) wishes to thank the Boards of Governors of Guy's Hospital and of the Bethlem Royal and Maudsley Hospitals for grants which made this long-term follow-up possible.

\section{REFERENCES}

Cordeau, J. P., and Mahut, H. (1964). Some long-term effects of temporal lobe resections on auditory and visual discrimination in monkeys. Brain, 87, 117-190.

Falconer, M. A. and Seratetinides, E. A. (1963). A follow-up study of surgery in temporal lobe epilepsy. J. Neurol. Neurosurgy Psychiat., 26, 154-165.

Hill, D. (1958). Indications and contra-indications to temporal lobectomy. Proc. roy. Soc. Med., 51, 610-613.

Lansdell, H. (1962). A sex difference in effect of temporal-lobe neurosurgery on design preference. Nature (Lond.), 194, 852854.

Meyer, V. (1957). Cognitive changes following temporal lobectomy for the relief of focal temporal lobe epilepsy. Ph.D Thesis, University of London.

- (1959). Cognitive changes following temporal lobectomy for relief of temporal lobe epilepsy. A.M.A. Arch. Neurol. Psychiat., 81, 299-309.

- and Yates, A. J. (1955). Intellectual changes following temporal lobectomy for psychomotor epilepsy. J. Neurol. Neurosurg. Psychiat., 18, 44-52.

Milner, B. (1954). Intellectual function of the temporal lobes. Psychol. Bull., 51, 42-62.

- (1958). Psychological defects produced by temporal lobe excision. In The Brain and Human Behavior, pp. 244-257. [Res. Publ. Ass. nerv. ment. Dis., 36.] 